\title{
Survey-Based Accident Analysis for Human-Powered Three-Wheeled Vehicles
}

\author{
Toni Wilhelm, ${ }^{1}$ Volker Dorsch, ${ }^{1}$ and Frank Gauterin ${ }^{2}$ \\ 'Ostfalia University of Applied Sciences, Germany \\ ${ }^{2}$ Karlsruhe Institute of Technology, Germany
}

\section{Abstract}

The causes of accidents involving nonconventional bicycle types have hardly been investigated in the literature to date. However, these vehicles could play an important role in reducing the $\mathrm{CO}_{2}$ emissions generated by traffic. As a basis for improving the driving safety of these environmentally friendly vehicles, this article presents the results of a survey on accidents and near-accidents of multitrack bicycle vehicles. More than 120 critical or accident situations of 86 drivers were analyzed. The situations are investigated with respect to the circumstances, the causes, and the consequences of the accidents using manual analysis and multiple correspondence analysis. A distinction is made between single accidents and accidents with another party. The aim of the survey is not to make statistically accurate statements on the frequency and probability of accidents, but rather to analyze the accident or near-accident circumstances. It is shown that the causes of single accidents are usually too high cornering velocities in combination with other factors such as road conditions. In the case of accidents with external involvement, the person who caused the accident is usually the other party involved. The accident opponent is in most cases a passenger car. Here the overlooking of the vehicles is the most frequent cause of accidents. Finally, possibilities to reduce the probability of accidents are briefly discussed for the different situations. As the research shows, most of the situations described occur on the road. This indicates that there are deficits in the bicycle infrastructure for the vehicles considered here. The results also indicate that there are deficits with regard to the perceptibility of the vehicles by other road users.

\section{History}

Received: 15 Mar 2021 Revised: 18 Jun 2021 Accepted: 30 Sep 2021 e-Available: 12 Oct 2021

\section{Keywords}

Three-wheeled vehicle, Accident, Bicycle, Humanpowered vehicle, Accident analysis

\section{Citation}

Wilhelm, T., Dorsch, V., and Gauterin, F., "Survey-Based Accident Analysis for Human-Powered ThreeWheeled Vehicles," SAE Int. J. Trans. Safety 10(1):2022, doi:10.4271/09-10-01-0001.

ISSN: 2327-5626 e-ISSN: 2324-5634

(c) 2022 The Authors. Published by SAE International. This Open Access article is published under the terms of the Creative Commons Attribution License (http://creativecommons.org/licenses/by/4.0/), which permits distribution, and reproduction in any medium, provided that the original author(s) and the source are credited.

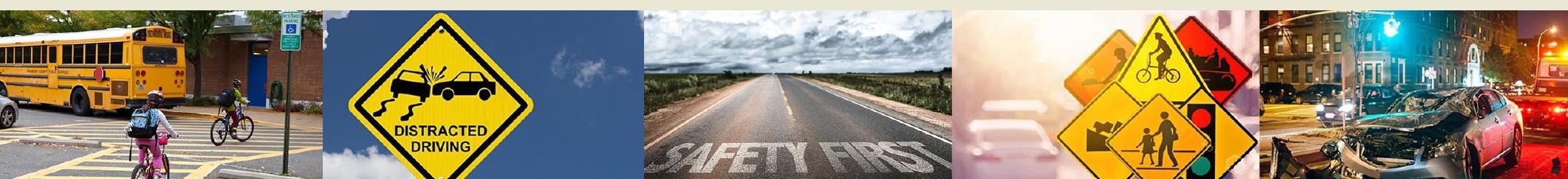




\section{Introduction}

rogressive climate change makes it necessary to use alternative transportation concepts to reduce $\mathrm{CO}_{2}$ emissions from transport. Bicycles can play a decisive role in this context over short distances $[1,2]$. In addition to classic bicycles, multitrack concepts such as trikes or velomobiles are becoming more and more common. Velomobile bicycles in particular are also suitable for medium distances, such as the daily trip to work [3] . With their aerodynamic outer skin, they allow efficient travel while at the same time providing protection against environmental influences. Velomobiles and trikes are not very common so far. Lohmeyer $[\underline{4}, \underline{5}]$ estimates about 1500 velomobiles in Germany in 2017, in Europe about 7000. Figures for other multitrack bikes hardly exist. According to a report of the German Ministry of Transport, less than $0.5 \%$ of the bicycles sold in 2013 in Germany were recumbent bicycles, cargo bikes, or other vehicles [6]. Only a small amount of these vehicles will be multitrack vehicles. Even if these vehicles are not very widespread so far, it is to be expected that in the course of the decarbonization of individual traffic a larger number of such bicycle vehicles will come onto the roads. Examples for both vehicle categories (trikes and velomobiles) are shown in Figure 1.

Both vehicle types are usually three-wheeled with two wheels at the front axle. Vehicles of this configuration are often called tadpole. The opposite configuration (one wheel in front, two in the back) is called delta.

Due to the low numbers, scientific studies of these vehicle types are almost completely missing. This also applies to critical driving situations and accidents, which could serve as the basis for optimizing driving safety. Within the framework of these investigations, a first step is to be taken in the accident analysis of multitrack bicycle vehicles. This mainly involves single-seater, multitrack recumbent bicycles for individual passenger transport with or without additional electric drive. The aim of the investigations is to identify critical driving situations and their circumstances for this vehicle class in order to create a basis for further vehicle dynamics analyses.

FIGURE 1 (a) Trike and (b) velomobile.

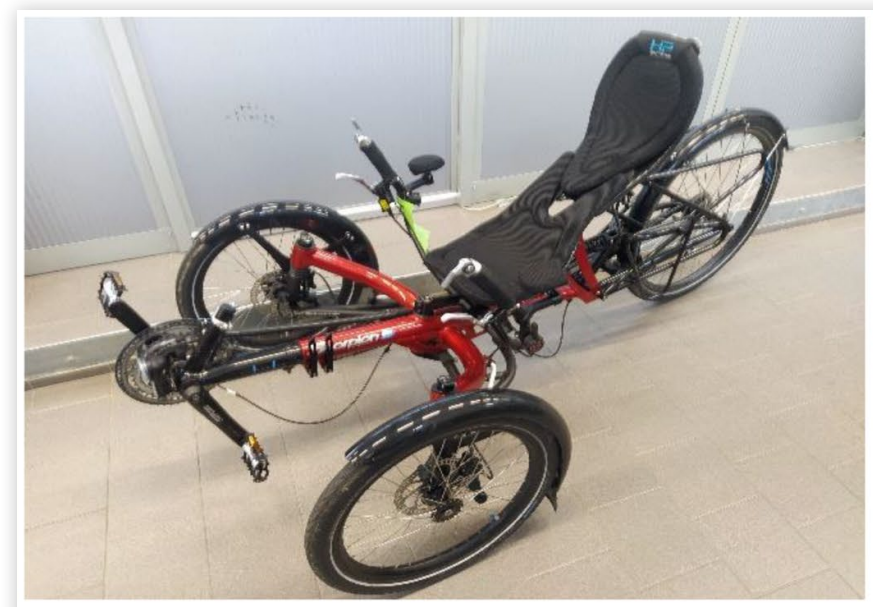

(a)

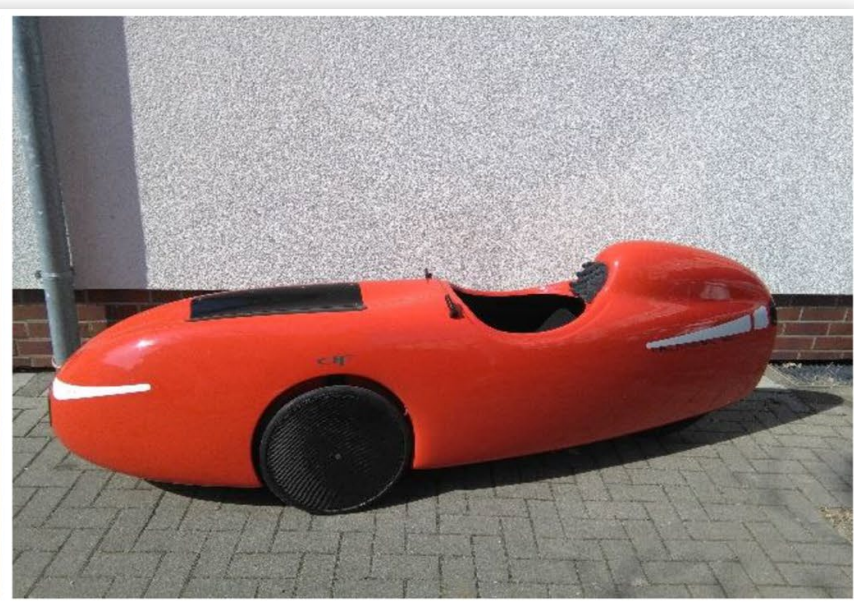

(b) 


\section{Literature Review}

Accidents involving conventional bicycles have been a focus of accident research for quite some time. A study by the NHTSA [7] examined typical accident sequences between bicycles and motor vehicles. Some studies are based on hospital statistics and survey of bicycle drivers that had been treated in hospital after an accident $[\underline{8}, \underline{9}]$. Other sources might be insurance data like in [10]. Not every accident necessarily leads to hospitalization and usually only a very small proportion of bicycle accidents are recorded by the police [11], which is especially the case for single accidents. For this reason, little accident data often appear in official databases and statistics. Due to the lack of objective data the field of accident research for bicycles often relies on self-reported surveys similar to that used in $[12,13,14]$. The disadvantage of survey-based studies is a lack of objectivity in the data collected, since the participants' statements cannot be verified.

According to Schepers et al. [15], between $60 \%$ and $95 \%$ of the cyclists admitted to the hospital were injured in a single accident. In [16], accident scenarios and determining factors are examined on the basis of over 1000 survey results of cyclists who have been involved in accidents. According to this, accidents involving third parties, accidents involving commuters, and accidents involving cyclists over 60 years of age are particularly common. From the data obtained, the severity of accidents is derived for the different accident scenarios. Schepers [] categorizes single accidents with regard to the triggering factors. According to this, about half of the accidents are related to the bicycle infrastructure. This includes collisions with obstacles caused by an unintentionally dangerous driving line or slippery or uneven road surfaces. The accident consequences of pedelecs and other electrically assisted bicycles are investigated in comparison to accidents of conventional bicycles by $[17, \underline{18}, \underline{19}]$. Wisch et al. [20] investigate accident scenarios of car-bicycle accidents analyzing several accident databases for the European project PROSPECT. Situations in which cyclists and cars are driving in the same direction are the most frequent cause of death in rural areas. In the city, situations in which the cyclist comes from the right lead to the most severe accidents. Fatal single-bicycle accidents account for a significant $25 \%$ of all fatal bicycle accidents, according to Wisch et al. [20].

So far, nonconventional types of bicycles have been largely ignored. First investigations in this direction were carried out by Bunte and Hipp [21] as part of a survey by the German Human Powered Vehicles Association (HPV). The survey covered accidents of special bikes in the following categories: two-wheeled recumbent bikes (recumbent), three-wheeled bikes (trikes), and faired recumbent bikes (velomobiles). About $40 \%(n=64)$ of the studied accidents refer to multitrack bicycle vehicles. Most of the single accidents that account for $60 \%$ of all collected accidents are attributed to causes in the transport infrastructure. These can be slippery roads, curbs, or traffic circles. In most cases (about 50\%), the cause of a single accident is attributed to excessive speed. Heavy braking or technical problems are of minor importance ( $<10 \%$ each). Compared to the other groups, accidents involving velomobiles tend to occur more frequently on the road, which is due to the fact that the velocity, dimensions, and limited maneuverability of these vehicles make them less suitable for conventional bike lanes. The accident sequence such as the vehicle reaction (rollover, skidding) is not discussed in detail. According to the study only $1.8 \%$ of accidents involving recumbent bicycles and $4.8 \%$ of accidents involving velomobiles were recorded by the police. In comparison, velomobile riders show a slightly lower injury rate than riders of open vehicles. Cars were involved in the vast majority (approx. 80\%) of the accidents involving another party.

More recent investigations in the field were conducted by Ayres [22]. A survey, this time among American users of recumbents, was also conducted to record accidents. A total of 129 accidents were investigated, of which $26 \%$ were accidents involving threewheeled vehicles. The main focus of this study was on the consequences of accidents. According to the results, accidents involving recumbents lead to head injuries significantly less often (11.1\% vs. $25.3 \%$ ) than accidents involving conventional bicycles. Reasons could be the lying position, the resulting lower fall height, and lower probability of a frontal rollover. On the other hand, recumbent cyclists have a higher (41.7\% vs. $26.3 \%)$ 
risk of hand or arm injuries. About half of the accidents with third-party involvement are characterized by a car coming from behind and ramming the bicycle, pushing off to the side, or cutting in immediately in front of the bicycle. High velocities, cornering, and uneven surfaces are reported as possible causes of rollover for the threewheeled vehicles.

\section{Materials and Methods}

A reliable database for the investigation of bicycle accidents involving multitrack vehicles is hardly available. Due to the small number of these vehicles and the low police registration rate of such accidents, there are no usable statistical accident data. A preliminary inquiry to the German accident database GIDAS resulted in only a few registered accidents involving multitrack bicycle vehicles [23]. The only remaining possibility for the investigations aimed at here is thus a direct questioning of drivers of such vehicles. This means some advantages and disadvantages for the significance of the results. In contrast to most accident investigations, which are based on hospital data as in [24], accidents can also be recorded here where there was no personal injury. In addition, critical driving situations can be queried that did not lead to an accident, but still provide information about frequent accident triggers. The disadvantage of the chosen methodology is that the survey participants belong to a self-selecting group, which means that the representativeness regarding the total group of all drivers of corresponding vehicles cannot be guaranteed. The survey thus also depends on the subjective description of how the accident occurred, which may be distorted due to personal perception, for example, on the question of accident responsibility in accidents involving other parties. Furthermore, no statistical comparisons with other means of transport can be made on this basis.

A passive recruiting process was used to attract the survey participants. The link to the survey was therefore published in a forum for users of unconventional bicycles. The forum is mainly used by German drivers or drivers from neighboring countries of Germany. The survey participants were first asked for general personal information such as age, gender, and riding experience. Afterwards, the participants had the opportunity to describe up to ten accidents or near-accidents in more detail. As already mentioned earlier, the aim of the survey is not so much to make statistical statements on the frequency and probability of accidents, but rather to analyze the accident circumstances. The survey consists of a combination of questions with given answer options (multiple choice) and questions with open text entries. The questions with predefined answers were used to roughly query the circumstances of the accident, such as year of accident, season, type of vehicle, road, and the like. In the free part, a detailed description of the accident should be given. This part is the more important part for the evaluation, because the free description results in a much more exact illustration of the accident circumstances than can be the case with predefined answer options. The free accident descriptions were analyzed and categorized. The rough classification is first of all done in the categories: single accidents, accidents with other parties, single near-accidents, and near-accidents with other parties. In the survey, situations that fulfill one or more of the following characteristics were defined as accidents:

- Collision with other participants or the environment

- Rollover of the vehicle

- Any case where the vehicle was damaged, or the driver injured

In the survey, situations that meet one or more of the following characteristics were defined as near-accidents:

- Short-term loss of control without significant consequences

- Near-collisions with other participants or the environment

- Could have resulted in an accident under slightly different circumstances 
For the individual accidents, an analysis of the circumstances of the accident and the effects of the accident is then carried out on the basis of the selected predefined answer options and the free accident description. Due to the relatively small amount of individual data, the evaluation of the results can mainly be done manually. In addition, a multiple-correspondence analysis is performed to determine factors that frequently occur together. There is no clustering of the various accident scenarios beyond the rough categorization as in [16], because the total number of situations described is considered too small for this purpose. The questionnaire can be found in Appendix A.

\section{Results}

The survey results are summarized in the following sections. Table B.1 gives an overview of the relative proportions of certain accident characteristics in the accident occurrence for the various categories.

\subsection{Driver Data}

The average age of the survey participants is 50.3 years (standard deviation [SD]: 9.9 years). Trike riders are on average slightly younger (49.8 years, SD: 11.5 years) than velomobile riders (50.8 years, SD: 9 years). The average age and age distribution of the survey participants show good agreement with the data in $[21,25]$. The age distribution can be found in Appendix C. On average, drivers have 6.8 years (SD: 5.3 years) of driving experience at the time of the survey. In terms of individual driving situations, drivers have an average of 4.1 years (SD: 4.3 years) of driving experience at the time of the situation described. The participants are predominantly male $(86 \%$, female $6 \%$, no information $8 \%$ ). The group consists of $67 \%$ velomobile riders and $33 \%$ trike riders. On average, the survey participants cover about $7500 \mathrm{~km}$ (SD: $4700 \mathrm{~km}$ ) per year with the surveyed multitrack vehicles. Velomobile riders drive an average of $8400 \mathrm{~km}$ (SD: 4900 $\mathrm{km})$ per year. Trike riders are significantly $(p=0.017)$ below this figure, averaging about $5700 \mathrm{~km}(\mathrm{SD}: 3800 \mathrm{~km})$.

\subsection{All Situations}

As already mentioned, this study divides the total number of incidents into four categories: single accidents, accidents with other parties, single near-accidents, and nearaccidents with other parties. About $26.8 \%$ of all described situations are single accidents, $27.6 \%$ are accidents involving others, $20.3 \%$ are near-accidents involving others, and $25.2 \%$ are single near-accidents. The distribution between the individual vehicle types is shown in Figure 2(a). A chi ${ }^{2}$-test reveals no significant relationship between type of vehicle and accident type $\left(\mathrm{chi}^{2}=0.80, p=0.85\right)$. The distribution of the reported situations in dependence of the year is shown in Figure 2(b). The majority of the situations (63\%) originate from more recent times, from 2018 onwards. However, this does not allow to conclude that accidents have increased during this period. The distribution of the different types of situations over the seasons is shown in Figure 2(c). In line with expectations, there is an increase in the number of reported accidents in the summer, as vehicles are probably used more often in this period. While the number of reported accidents for velomobiles is almost constant over the rest of the year with a slight increase in winter, there is a decrease in accidents for trikes in winter. This is due to the fact that velomobiles have a certain degree of weather protection with their aerodynamic fairing, which is why these vehicles are also suitable for use in winter. This characteristic is missing with trikes, so they are used less in winter. There is an increase in described single situations for velomobiles in winter, which might be due to more difficult road conditions. Besides this, a statistical statement of the probability of accidents in the seasons is not possible, since it is not known how many kilometers are covered on average in the individual seasons. 
FIGURE 2 (a) Number of situations by category and vehicle type; (b) number of situations by year; (c) seasonal distribution of situations by vehicle type and involvement of another party; (d) distribution of velocity by vehicle type.

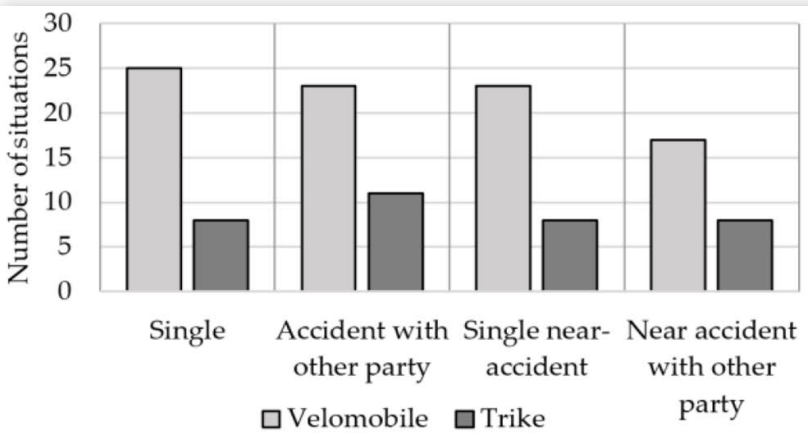

(a)

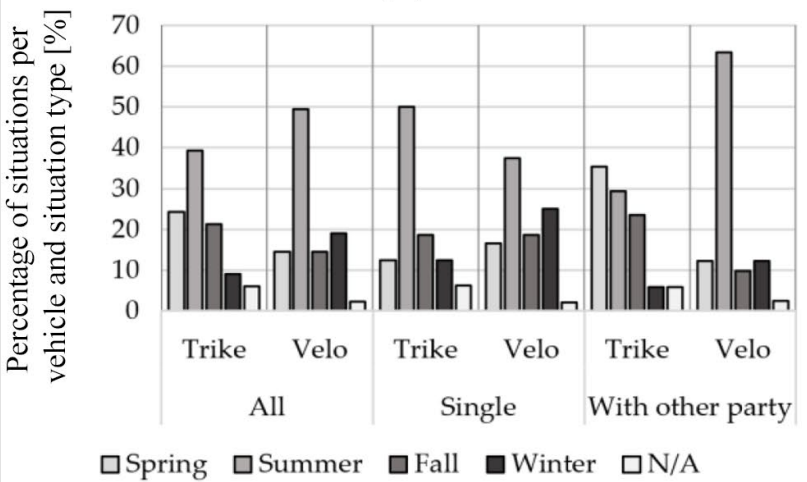

(c)

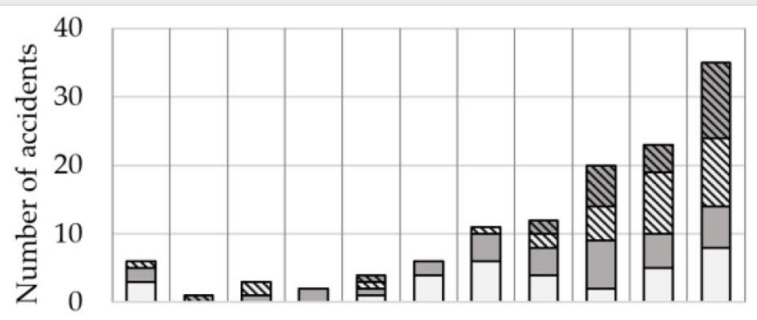

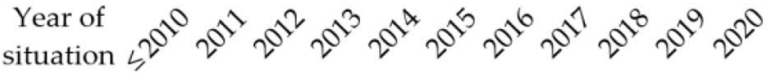
口Single

$\mathbb{\$}$ Single near-accident

$\square$ Accident with other party $\mathbb{N}$ Near accident with other party (b)

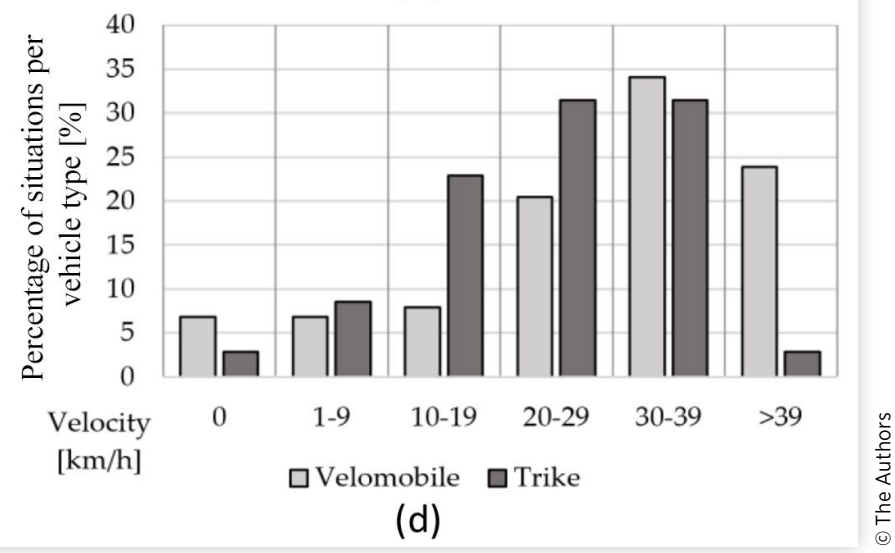

Figure 2(d) shows the distribution of velocity in dependence of vehicle type, for all situations described. According to this, velomobiles are significantly $(p=0.012)$ faster at the time of the incident with an average velocity of $28.6 \mathrm{~km} / \mathrm{h}(\mathrm{SD}=15.2 \mathrm{~km} / \mathrm{h})$ than trikes with an average of $21.6 \mathrm{~km} / \mathrm{h}(\mathrm{SD}=9.6 \mathrm{~km} / \mathrm{h})$. Most of the situations described took place on the road (79.7\%). A smaller proportion of incidents were described on bike paths (16.3\%) and very few situations on other or unpaved paths (4.1\%). No significant differences in the use of different types of lanes are shown between the different vehicles. Situations with third-party involvement tend to occur more frequently on the road than situations without third-party involvement $\left(86.4 \%\right.$ vs. $73.4 \%$, chi $\left.^{2}=5.77, p=0.058\right)$.

Figure 3 shows the severity of injuries for all accidents (i.e., without near-accidents) in dependence of the velocity [Figure 3(a)] and vehicle type [Figure 3(b)]. It can be seen that there is a high number of accidents with injuries in the low speed range $(1-9 \mathrm{~km} / \mathrm{h})$. In these situations, accidents with third-party involvement predominate. In the higher speed range starting from $20 \mathrm{~km} / \mathrm{h}$ the development corresponds to the expectation that higher accident speeds lead to more serious injuries. In this velocity range, single accidents occur predominantly. Velomobile riders show a slightly lower injury rate (42\%) compared to trike riders (52\%) across all actual crashes. Due to the limited amount of data, this difference cannot yet be considered significant $(p=0.414)$. There is nevertheless a significant difference $(p=0.042)$ in the velocity of the actual accidents. The average speed for velomobiles was $26.2 \mathrm{~km} / \mathrm{h}(\mathrm{SD}: 15.1 \mathrm{~km} / \mathrm{h}$ ) and for trikes $18.1 \mathrm{~km} / \mathrm{h}$ (SD: 10.1 $\mathrm{km} / \mathrm{h}$ ). Although velomobiles were significantly faster than trikes at the time of the accident, there is no significantly higher risk of injury. Velocity is proven to be an important factor for accident severity in bicycle accidents [26]. It seems plausible that the aerodynamic hull of velomobiles prevents injuries associated to direct contact of the rider with the surroundings, especially during rollovers, which may lead to less frequent and less severe injuries overall. 


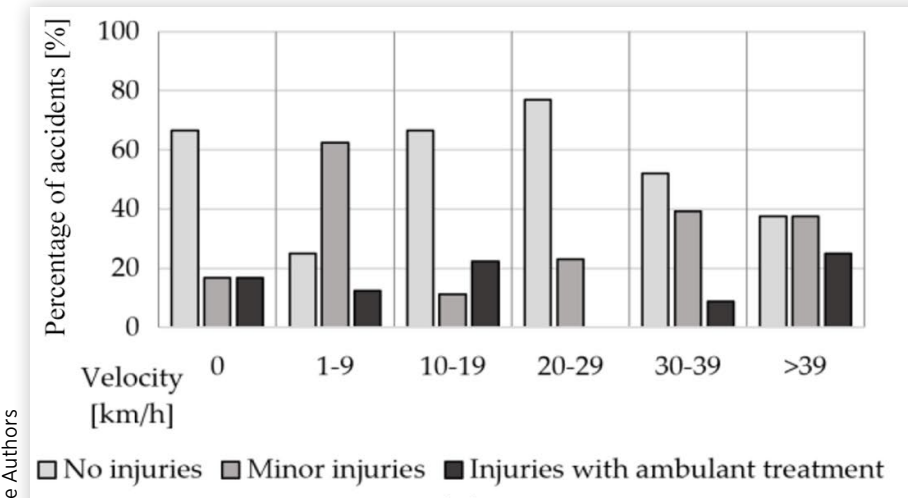

(a)

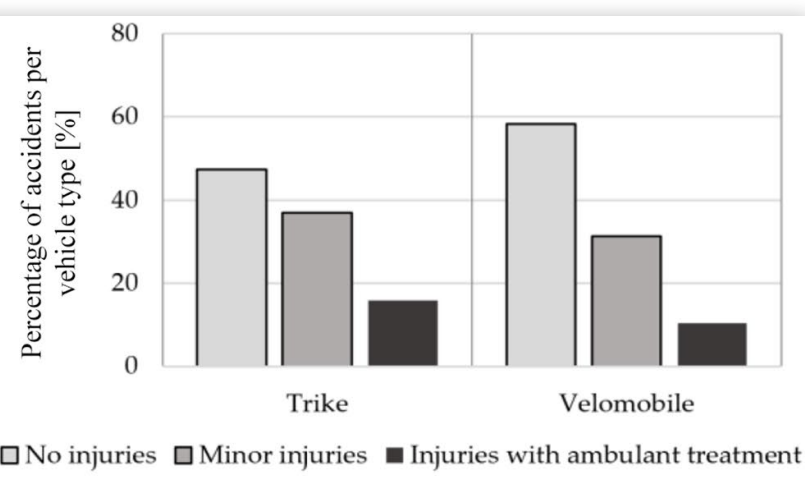

(b)

\subsection{Single Accidents}

Table 1 gives an overview of occurring factors and causes in single accidents. It shows the percentage of situations in which the corresponding cause played a role. Since several causes can occur together, the sum of all percentages is above 100\%. A high number of single accidents is related to the fact that the speed was too high for the existing conditions such as curve radius or grip of the road surface. The comparison of velocities shows significant differences $(p=0.025)$ of the vehicle types. The average velocity of velomobiles at the time of the single accident as estimated by the participants as $32.8 \mathrm{~km} / \mathrm{h}$ (SD: 12.9 $\mathrm{km} / \mathrm{h}$ ), which is significantly higher than the average velocity of trikes with $21.0 \mathrm{~km} / \mathrm{h}$ (SD: $10.0 \mathrm{~km} / \mathrm{h}$ ). The main reason for single accidents is often unfavorable road conditions combined with excessive driving speed. About $75 \%$ of the accidents due to road conditions can primarily be attributed to reduced friction coefficients (slippery) and $25 \%$ primarily to road unevenness. Often a slight lifting of the rear wheel due to the unevenness is described here. Since there is usually only one wheel at the rear, the track guidance is lost due to missing lateral force transmission. This leads to oversteering of the vehicle and results in the vehicle being turned sideways and rolling over.

In $15 \%$ of cases, the accident description indicates understeering behavior and thus reduced steerability based on low lateral force potential on the front axle. In $75 \%$ of the cases, this resulted in a collision with surrounding objects. A significant difference ( $p=$ 0.005 , exact Fischer) exists to situations in which oversteer and thus a loss of stability is described (27\% of the single accidents). These led to a rollover of the vehicle in all cases. In total a rollover is the consequence of $79 \%$ of all single accidents. In the remaining

TABLE 1 Accident causes for single accidents (combination of participants answers and categorization based on accident description).

\begin{tabular}{|l|l|l|}
\hline Single accident causes & $\begin{array}{l}\text { Number of } \\
\text { situations }\end{array}$ & $\begin{array}{l}\text { Percentage of single } \\
\text { accidents (\%) }\end{array}$ \\
\hline High velocity & 22 & 67 \\
\hline Unfavorable road conditions & 16 & 49 \\
\hline Friction coefficient (wet/slippery/icy) & 13 & 40 \\
\hline Unevenness & 8 & 24 \\
\hline Street course/Curvature/High steering angle & 8 & 24 \\
\hline Avoidance maneuver & 2 & 6 \\
\hline Crosswind & 2 & 6 \\
\hline Accident with animals & 2 & 6 \\
\hline Conditions of visibility & 1 & 3 \\
\hline Others & 2 & 6 \\
\hline
\end{tabular}


cases the vehicle collided with surrounding structures. A velocity not adapted to the course of the road is also a frequent reason for single accidents of the considered vehicles. Thus, some accidents can be traced back to poorly visible curves or curves with unsteady curvature. On the basis of the single accidents it becomes clear that vehicle rollover over is one of the greatest dangers of these multitrack bicycle vehicles. Overall, about $46 \%$ of the accidents resulted in personal injury. In $87 \%$ of the accidents with personal injury, the injuries were so minor that they did not require medical attention. In the remaining cases, ambulant medical care was sufficient. Velomobile riders were subject to a smaller incidence of injury (40\%) than trike riders (62\%). As in the analysis for all accidents, this difference cannot yet be considered significant due to the low absolute numbers ( $p=$ 0.42 , exact test according to Fischer). As velomobiles are significantly faster at the time of the accident but show similar or on average slightly lower severity and frequency of injuries, a protective effect of the aerodynamic chassis might again be assumed here. Only $6 \%$ of the situations were recorded by the police.

\subsection{Accidents with Other Party}

Thirty-four cases of accidents with third-party involvement were recorded in the survey. About $38 \%$ of the reported accidents were recorded by the police. In two-thirds of the cases velomobiles and in one-third trikes were affected. Only in about $15 \%$ of the accidents, according to the surveyed riders, the fault lies with them. This might be biased, as there is no objective evidence. Almost $80 \%$ of these cases are due to errors of right of way when turning. In these cases another road user was usually overlooked. In those cases where the other party is at fault, $76 \%$ of the drivers state that they were overlooked by the other party. Almost $76 \%$ of the other parties are cars, vans, or trucks, $10 \%$ are motorized two wheelers, $10 \%$ are bicycles, and $4 \%$ are pedestrians.

In the case of accidents with the fault of the opponent, two larger groups appear. One group includes classic priority errors such as ignoring the right-of-way when turning left or turning into a street with priority. These cases together count for about $36 \%$ of the accidents with opponent's fault. Within this group, about half of the cases are due to errors when turning left. In slightly less than half of the cases, the trike or velomobile was driving on a bicycle path. About $31 \%$ of the opponent's fault situations are characterized by rear-end collisions with the trike or velomobile. Almost $56 \%$ of this cases happened in flowing traffic and mostly under good visibility conditions. In the rest of the cases the vehicle was standing still, e.g., waiting at a red traffic light or just starting up.

Almost $45 \%$ of the accidents ended with personal injury. Of these, $60 \%$ were minor injuries without the need for medical treatment. The remainder were personal injuries with ambulant medical treatment. The relative proportion of injured drivers is about the same as for single accidents, although the degree of injury in accidents involving third parties is on average slightly higher $\left(\mathrm{chi}^{2}=2.73, p=0.21\right)$. For multitrack vehicles similar accident configurations can be observed for on-road accidents as were shown for conventional bicycles in [16] and [20]. However, in contrast to the above-mentioned investigations, the velomobiles and trikes move on the road much more often. In about $82 \%$ of the accidents here, the vehicles drove on the road. It becomes clear that the poor perceptibility of the examined vehicles represents a clear risk factor. Therefore, methods have to be developed to ensure improved visibility and detection by other drivers and vehicles. Additional studies of the perception of those unconventional vehicles by other drivers might be useful in this context.

\subsection{Single Near-Accidents}

In order to be able to build the investigations on a larger database, the survey participants were not only asked about situations in which an accident occurred, but also about critical situations in which an accident could just about be avoided. Of the reported 
FIGURE 4 Relative proportion of causes for single accidents and near-accidents.

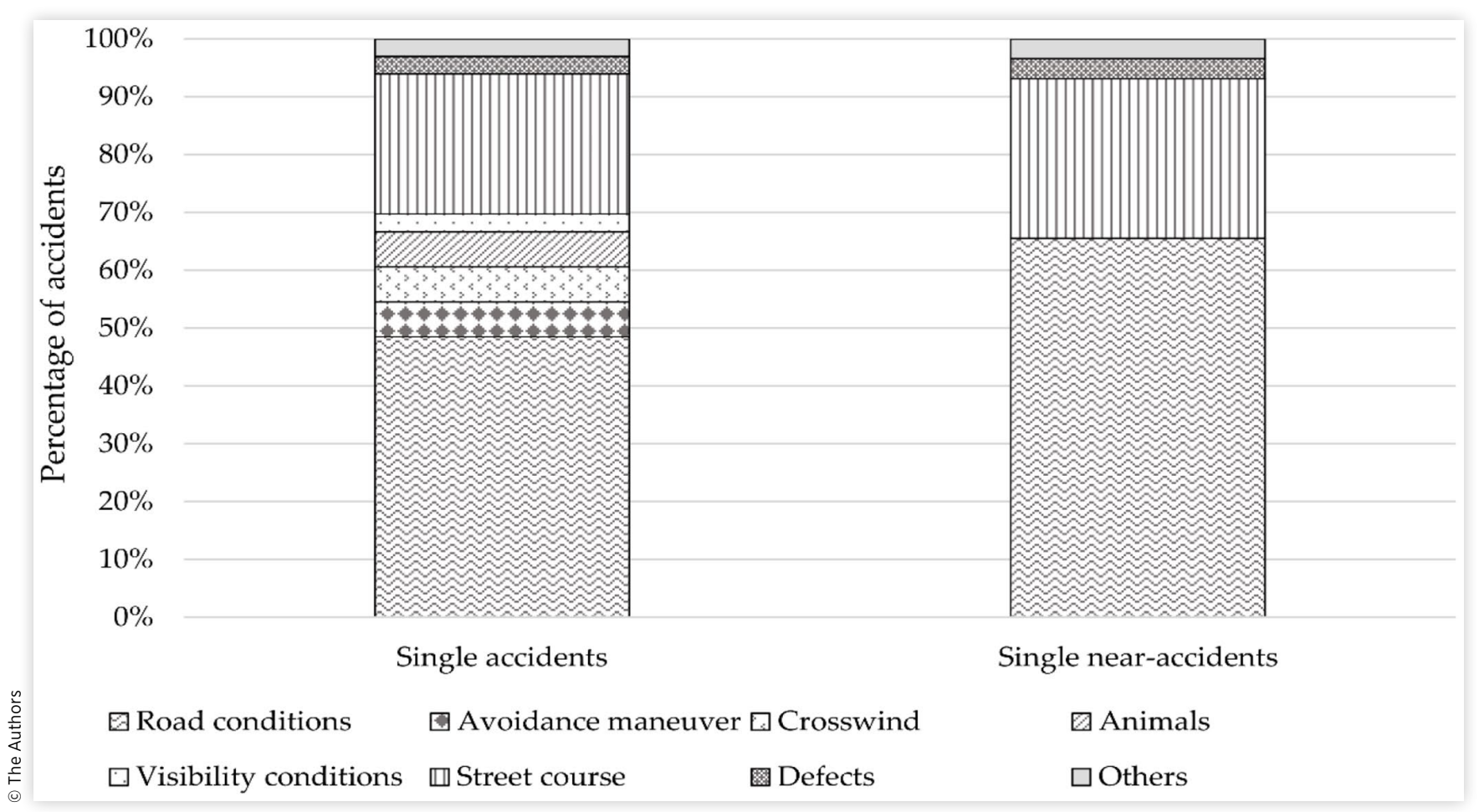

near-accidents, 53\% represent situations without outside involvement. Figure 4 shows a comparison of the main reasons for single accidents and single near-accidents.

As can be seen from the graph, the circumstances of actual and near-accidents are similar as expected. Also in the case of near-accidents, situations dominate where too high vehicle speed in combination with the road conditions led to a critical driving situation. Oversteering and slipping of the vehicle were reported in 35\% of these cases. Other effects described are near-collisions (25\%), runoff from the road (15\%), nearrollover (15\%), and other effects (10\%). About $25 \%$ of the cases are related to a velocity that is not adapted to the course of the road. Near rollover was reported in $25 \%$ of these cases. The rest of these situations resulted in oversteering.

\subsection{Near-Accidents with Other Party}

Of the described near-accidents with other participants, $76 \%$ are attributed to the fact that they were overlooked by the other person involved. In $68 \%$ of these situations, this was expressed as a right-of-way error when turning. The velomobile or trike riders were usually driving on the road (77\%). In $23 \%$ of the cases the velomobile or trike moved on the bike path. The other participants are predominantly cars with $92 \%$. In $12 \%$ of the cases, a situation is described in which one's own vehicle was hidden by buildings (e.g., flower boxes) or parked vehicles.

\subsection{Multiple Correspondence Analysis}

Multiple correspondence analysis (MCA) is a tool which, in the context of these accident investigations, enables the presentation of factors that frequently occur together. Thus it allows to calculate the relations between different accident properties. 
Variable characteristics are given scores that are ranked by importance and can be displayed in a low-dimensional space [27]. Every value of a property is transformed into an own column and expressed in binary. From the column accident type, for example, four new columns for the different types (single, with other party, single near, near with other party) are created. Depending on the actual accident type of the current row, the corresponding column is assigned a 1, the rest a 0 . In order to limit the number of columns in numerical fields such as speed or vehicle damage, a categorization takes place first (e.g., speeds between 1 and $20 \mathrm{~km} / \mathrm{h}$ get the characteristic value "low speed"). The situations described are the objects to be examined. Variables of the correspondence analysis are the individual accident characteristics as given by the multiple-choice answers of the participants. The properties of the driver are not taken into account, because one driver could specify several accidents. The consideration of the driver properties would therefore mean a distortion toward properties of drivers with many registered accidents. The categories and main accident reasons assigned on the basis of the free accident description by the authors are not directly included in the calculation but are shown as supplementary variables. For more information on MCA and the background of the calculation, please refer to Greenacre [27]. The calculations are performed with xlstat (version 2020.5).

Figure 5 shows the results of the MCA. Note that the closer a point is to the center, the less specific is the corresponding property. Conversely, far away points are very specific. Points that are closer together are more closely related to each other. Therefore they occur more often together. Some of the less significant points (especially the negations of the various possible causes of accidents) are not shown for reasons of clarity. As can be seen from the MCA, the type of vehicle, low and medium speeds, and the seasons, with the exception of winter, are close to the center of the diagram and therefore not significant for the specific types of accidents. Also not significant is driving on the road, which can be associated with all types of accidents to about the same extent. Off-road driving on unpaved roads, on the other hand, is more strongly associated with single accidents and single near-accidents. Winter correlates more strongly with single nearaccidents and slippery road conditions. Understeer and oversteer are strongly correlated with road conditions and are characteristic of single accidents or single near-accidents. Similarly, high speeds, excessive steering angles, and uneven road surfaces are characteristic of these types of accidents. Minor injuries correspond to minor or medium vehicle damage. Large vehicle damages $(>1000 €)$ and more serious injuries correspond more to accidents with third-party involvement than to single accidents. A high significance for an accident with external involvement is shown by the speed $0 \mathrm{~km} / \mathrm{h}$. There is also a correlation here with rear-end collisions, which often occurred while the vehicle was stationary. Passenger cars are more or less similarly characteristic as opponent for both accidents and near-accidents with third-party involvement. Being forced out of the way and overtaking mistakes by another road user are more characteristic of nearaccidents. These situations are thus perceived as critical, but actual accidents here could almost always be avoided.

The results of the MCA show great agreement with the results of the manual evaluation. In particular, it allows a clear presentation of the correlating factors. However, the manual evaluation cannot be completely replaced by the MCA, since only a part of the relationships can be reproduced by the two-dimensional illustration. Thus, important factors that are similarly distributed across all types of accidents appear to be of little significance, even though they might play a role for all accidents. An example is the distribution of accidents between street and cycle path. According to the MCA, neither parameter is particularly significant for the different types of accidents, with riding in the bike lane being somewhat more likely to correspond with actual accidents. However, the MCA does not show that a large proportion of the accidents described here took place on the street, which would allow conclusions to be drawn about the suitability of the cycling infrastructure for the vehicles considered here. 


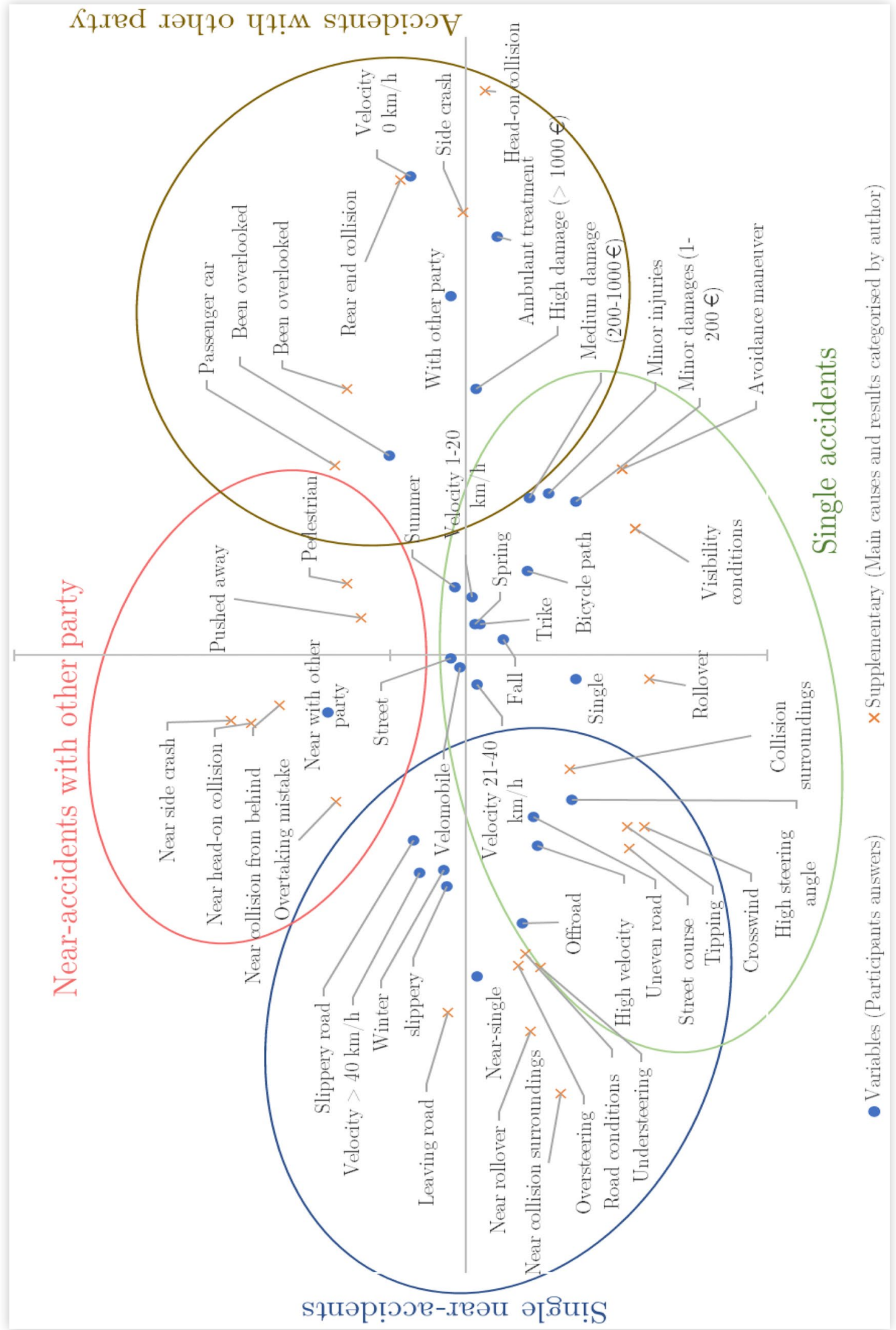




\section{Measures for Accident Probability Reduction}

Possible measures to reduce the probability are briefly discussed in the following section. The measures can be divided into two types based on the accident scenario: measures to reduce single accidents and measures to reduce accidents involving other parties. As has been shown, the reason for single accidents is usually an unadopted cornering speed. In the majority of cases this leads to rollover or near-rollover. The tendency to roll over is due to the vehicle design. For example, the maximum track width (which counteracts rollover) is limited by aerodynamic requirements, weight restrictions, and available lane widths. At the same time, the center of gravity height cannot be arbitrarily shifted downward for constructive reasons and to ensure a certain viewing height. To reduce the rollover propensity active and passive systems are basically conceivable. Active systems could, for example, work with the control variables, steering angle, and braking torque. A steering angle limiter or an active steering system could prevent a steering angle that is too large for a certain driving speed. The disadvantage, however, is that this inevitably results in a deviation from the target course. This could result in the vehicle drifting off the road or colliding with surroundings or other vehicles. A targeted braking intervention would have the advantage that the driving speed and thus the potential danger would be reduced. A brake intervention on the outer front wheel, for example, would have the effect of reducing the driving speed and at the same time reduce the lateral force potential on the front axle. Furthermore, the resulting moment around the center of gravity supports understeering behavior, which reduces risk of rollover. These effects result in a reduction of the lateral acceleration acting on the vehicle. Here, too, deviations from the desired lane are possible. Active systems such as the systems presented in [28] or [29] have the disadvantage that they require a high degree of sensor and actuator technology. This causes high cost and weight increases, which is why such systems probably cannot be established in this vehicle segment.

Passive systems have the advantage that they do not require actuators. It is conceivable, for example, to warn the driver of critical points along the route. Based on map data with known road curvature radii, the vehicle parameters could be used to determine the maximum possible cornering velocity. Taking weather data into account, it would also be possible to adapt to different road conditions. The use of cloud-based services, in which vehicles independently detect critical situations based on given criteria, would also be possible. In this case, the detected critical situations could be used to warn other vehicles. For such applications, simple sensor clusters, which almost everyone carries in the form of a cell phone, would probably be sufficient.

According to the investigations, being overlooked is the main reason for accidents of velomobiles or trikes with other participants. A lack of conspicuity and visibility is known as risk factors for traditional bicycles as well $[\underline{30}, \underline{31}]$. Based on the data collected, it cannot be verified that the low vehicle height poses a problem for the perceptibility by other road users. This would require studies on the detectability of these vehicles in road traffic. As the size comparison in Figure 6 shows, a correlation between vehicle height and detectability would at least be possible.

Structural changes to the vehicles are certainly not suitable to solve this problem, since larger vehicles contradict the idea of efficient transportation and a higher center of gravity has a negative influence on the rollover stability. Options for increasing visibility could include the use of bright colors or reflectors, as is also common with bicycle clothing. This, together with adequate lighting, is already used by velomobile manufacturers in many cases. Flags, which are often used for trikes according to the study of Ayres [] $]$, are not an option for velomobiles due to the aerodynamic disadvantages. More in-depth subject studies would be needed to examine the effectiveness of possible measures regarding visibility. A technically more complex solution that might be used in the future could be the integration into the planned Car2X communication. In this way, vehicles could draw attention to where and in which direction they are moving. Driver assistance systems in passenger cars could react accordingly and warn the own 


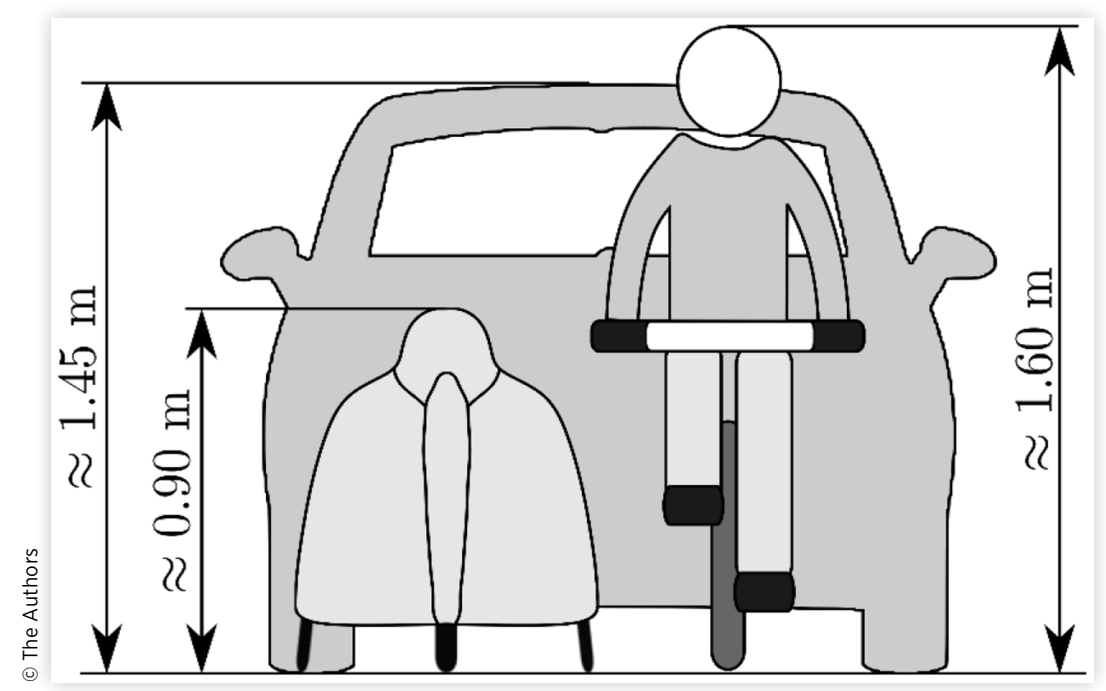

driver of an invisible vehicle, for example behind parked cars. In principle, it would be possible to imagine a solution in which no additional hardware would be installed in the vehicle, but instead the smartphone could be used as a means of communication and sensor cluster that is usually available anyway. Examples of such systems are described, for example, in [32, $\underline{33}]$.

\section{Discussion}

In the previous chapters, the main findings of the survey were presented for the different categories of accident situations. It should be noted that the data basis for these investigations is relatively small. The vehicles considered here are so far not very common. As the investigations show, only a small part of the accidents is recorded by the police or requires medical treatment in hospital. Low numbers and low reporting rates appear to be the reasons for the low number of recorded accidents in the GIDAS database. As is the case with many bicycle-related accident studies (see, for example, $[\underline{8}, \underline{9}, \underline{10}, \underline{12}, \underline{13}$, $\underline{14}, \underline{18}, \underline{21}, \underline{22}])$, the research conducted here had therefore to rely on a self-reported survey. The statistical significance remains limited, especially with regard to accident figures and distribution among the different categories. It is to be expected that the information provided by the participants on the accident situations does not always correspond to an objective view, especially in the case of accidents involving other road users. It is not possible to derive an accident probability and a direct comparison with other means of transport. However, the situations described give an impression of typical accident patterns for the vehicle class under consideration and thus possible approaches for improvements in driving safety.

Within the scope of the survey, the participants only described situations that were associated with minor, in the worst case, ambulatory injuries. From news researches, however, also heavy to deadly accidents result. These are not represented in the survey so far. Nevertheless, it could be shown what the main causes of accidents of these vehicles are. There is little difference between the causes of actual accidents and the corresponding near-accidents. It has been shown that in single accidents, inappropriate speed is the main cause of accidents, which is consistent with the results in [21]. This occurs in connection with other circumstances such as the road surface (slipperiness or unevenness, $49 \%$ ) or too large steering angle or too small cornering radius (24\%). Contrary to Schepers' [ $[$ ] findings, where unfavorable road conditions are blamed for about $25 \%$ of 
the single accidents, the proportion here is higher and agrees very well with the proportion of about $50 \%$ given by Utriainen [10] for single accidents. It is possible that countryand climate-specific differences might have an influence here. The studies by Utriainen [10] refer to Finland and by Schepers [ $[$ ] to the Netherlands. The Netherlands and Germany are climatically very similar, so the high difference might probably not be attributed to this. A possible explanation for the difference could be the different ways of obtaining participants. For Schepers studies, only accidents involving hospital treatment were considered. It might therefore be concluded that accidents based on road conditions lead to injuries less often for conventional cyclists than other types of accidents. Hence this type of accident might be underrepresented based on hospital statistics. Another possible reason could be that the vehicles considered here (especially the velomobiles) are more vulnerable to unfavorable road conditions due to their higher achievable speeds. Another factor is certainly that velomobiles travel less in dense inner-city traffic and on shared pedestrian and bicycle paths. As a result, collisions with obstacles, for example, which account for a significant proportion of single accidents in Schepers, are less likely. The investigations carried out here show that a collision rather occurs as a final result due to a loss of control because of high velocity and road conditions and not as an independent cause of the accident, as with Schepers. Another significant difference is that a high number (16\%) of single accidents at Schepers is attributed to the loss of control at low speeds. This does not apply to multitrack bicycle vehicles, since, unlike bicycles, they are inherently stable. In turn, oversteering behavior was described for a relevant proportion (27\%) of single vehicle accidents, resulting in a rollover in every case. Moreover, a rollover occurs in almost all single accidents (79\%). The data obtained might be used to draw conclusions about possible test maneuvers to characterize different vehicles. The frequently described situations can be approximated by simple maneuvers such as stationary cornering or increasing steer.

It can be stated that most of the reported situations happened on the road (approx. $80 \%$ ), which is much higher than the corresponding share of use for conventional bicycles (45\%-50\% according to []]). This suggests that the vehicles investigated here are moved more often on the road than on the bike path. Reasons for choosing the roadway were not recorded in the survey. One possible reason could be that the current bike infrastructure (especially the design of the bike lanes) might not be suitable for the vehicles studied here. The high speed, the width of the vehicles, and a lower maneuverability (larger turning circles) compared to traditional bicycles could be reasons for this. Bollards on cycle paths, for example, which are designed to prevent cars from entering, also represent an obstacle for these vehicles.

In accidents with other people involved, similar patterns are seen as presented for conventional bicycles in [20]. However, the proportion of rear-end collisions found here $(29 \%)$ is considerably higher than the proportion in [20] (10\%). This may result from the relatively higher road use of the vehicles considered here. Due to the low vehicle height, velomobiles and trikes might have additional problems with regard to visibility, e.g., behind peripheral buildings or other parked or moving vehicles.

\section{Conclusion and Future Work}

The aim of these investigations was to analyze the causes and consequences of accidents for multitrack bicycle vehicles. The results can be used as a basis for developing specific test maneuvers for targeted vehicle development and design. It could be shown that single accidents are mainly due to an inappropriate speed during cornering. Other important factors were road unevenness or reduced force transmission potentials due to wetness or ice. Oversteering is a frequently described problem, which in all cases led to a vehicle rollover. Specific investigations of the dynamic behavior of these vehicles could provide insights into improving driving safety in this regard. To reduce accidents, systems could help to mark critical points depending on the planned route and support the driver by displaying a vehicle-dependent maximum speed. This is essentially suitable for simple accident situations in which the vehicle begins to rollover due to excessive 
cornering speeds. With regard to accidents involving third parties, it is apparent that the vehicles considered here are often simply not perceived sufficiently as it is also the case for conventional bicycles. Additional studies on perceptibility of these vehicles could be used to identify improvement possibilities. A communication of the vehicles with their environment and with other vehicles could help other road users to perceive the vehicles earlier and better. A question that also needs to be considered in this context is to what extent such unconventional vehicles are considered in the training of assistance systems and autonomous driving functions.

Especially the velomobiles are in a field of tension between the slower conventional bicycles and the faster passenger cars. Thus, conflicts of use on the bike lane as well as on the road cannot be avoided. The introduction of separate lanes for fast bicycle vehicles such as velomobiles or pedelecs could ease the situation. For future studies, it remains to be seen which measures (infrastructural, regulatory, technical) have the potential to reduce the number or impact of accidents involving these vehicles, in addition to the options briefly mentioned here.

The survey will remain open so that new accident records can be collected on an ongoing basis in order to provide greater statistical information on the causes and effects of accidents on these vehicles.

\section{Acknowledgment}

The authors would like to thank all participants of the accident survey for their time and willingness to contribute to improving the driving safety of the considered vehicles.

\section{References}

1. Ahrens, G.-A., Becker, U., Böhmer, T., Richter, F.M. et al., "Potenziale des Radverkehrs für den Klimaschutz-Kurzfassung (Potentials of Cycling for Climate Protection-Short Version)," Ministry Report, German Federal Environmental Agency, 2013.

2. Massink, R., Zuidgeest, M., Rijnsburger, J., Sarmiento, O. et al., "The Climate Value of Cycling," Natural Resources Forum 35 (2011): 100-111, https://doi. org/10.1111/j.1477-8947.2011.01345.x.

3. Van De Walle, F., "The Velomobile as a Vehicle for more Sustainable Transportation," Master's thesis, Royal Institute of Technology Stockholm, Stockholm, 2004.

4. Velostrom, "Velomobile: Hocheffiziente Fahrräder für das ganze Jahr (Velomobiles: Highly Efficient Bikes for All Year Round)," accessed October 30, 2020, https://www. velostrom.de/velomobile-hocheffiziente-fahrraeder-fuer-das-ganze-jahr/.

5. Lohmeyer, D., Velomobile: Schnelle Fahrräder mit Wetterschutz (Velomobiles: Fast Bikes with Weather Protection), 1st ed. (Windeck: LD-Verlag, 2018), ISBN:978-3-9806385-7-9.

6. Bracher, T. and Hertel, M., "Radverkehr in Deutschland-Zahlen, Daten, Fakten (Cycling in Germany-Numbers, Data, Facts)," Ministry Report, German Federal Ministry of Transport and Digital Infrastructure, 2014.

7. Cross, K. and Fisher, L., "A Study of Bicycle/Motor-Vehicle Accidents: Identification of Problem Types and Countermeasure Approaches," Ministry Report, NHTSA, 1977.

8. Schepers, P. and Klein Wolt, K., "Single-Bicycle Crash Types and Characteristics," Cycling Research International 2 (2012): 119-135.

9. Airaksinen, N., Lüthje, P., and Nurmi-Lüthje, I., "Cyclist Injuries Treated in Emergency Department (ED): Consequences and Costs in South-Eastern Finland in an Area of 100,000 Inhabitants," Annals of Advances in Automotive Medicine 54 (2010): 267-274.

10. Utriainen, R., "Characteristics of Commuters' Single-Bicycle Crashes in Insurance Data," Safety 6 (2020): 13, https://doi.org/10.3390/safety6010013.

11. Shinar, D., Valero-Mora, P., van Strijp-Houtenbos, M., Haworth, N. et al., "UnderReporting Bicycle Accidents to Police in the COST TU1101 International Survey: Cross- 
Country Comparisons and Associated Factors," Accident Analysis and Prevention 110 (2018): 177-186, https://doi.org/10.1016/j.aap.2017.09.018.

12. Popa, I., Ferraro, O., Orsi, C., Morandi, A. et al., "Bicycle Helmet Use Patterns in Italy. A Description and Analysis of Survey Data from an Italian Friends of Cycling Association," Accident Analysis and Prevention 108 (2017): 268-274, https://doi.org/10.1016/j. aap.2017.09.003.

13. Fyhri, A., Johansson, O., and Bjørnskau, T., "Gender Differences in Accident Risk with e-Bikes-Survey Data from Norway," Accident Analysis and Prevention 132 (2019): 105248, https://doi.org/10.1016/j.aap.2019.07.024.

14. Gildea, K. and Simms, C., "Characteristics of Cyclist Collisions in Ireland: Analysis of a Self-Reported Survey," Accident Analysis and Prevention 151 (2021): 105948, https://doi. org/10.1016/j.aap.2020.105948.

15. Schepers, P., Agerholm, N., Amoros, E., Benington, R. et al., "An International Review of the Frequency of Single-Bicycle Crashes (SBCs) and Their Relation to Bicycle Modal Share," Injury Prevention 21 (2015): 138-143, https://doi.org/10.1136/ injuryprev-2013-040964.

16. Billot-Grasset, A., Viallon, V., Amoros, E., and Hours, M., “Typology of Bicycle Crashes Based on a Survey of a Thousand Injured Cyclists from a Road Trauma Registry," Advances in Transportation Studies 2 (2014): 17-28, https://doi. org/10.4399/97888548735373.

17. Otte, D., Facius, T., and Müller, C., "Pedelecs im Unfallgeschehen und Vergleich zu konventionellen nichtmotorisierten Zweirädern (Pedelec Accidents in Comparison to Conventional Non-Motorized Two-Wheelers)," VKU Verkehrsunfall und Fahrzeugtechnik 52 (2014): 48-60.

18. Panwinkler, T. and Holz-Rau, C., "Unfallgeschehen von Pedelecs und konventionellen Fahrrädern im Vergleich (Accidents of Pedelecs and Conventional Bicycles in Comparison)," Zeitschrift für Verkehrssicherheit 5 (2019): 336-347.

19. Xing, Y., Sun, Z., and Wang, D., "Investigating Influence Factors on Injury Severity of Electric and Non-electric Bicycle Crashes in Beijing," in Proceedings of the 2020 IEEE 5th International Conference on Intelligent Transportation Engineering (ICITE), Beijing, China, September 11-13, 2020, IEEE, 606-610, https://doi.org/10.1109/ ICITE50838.2020.9231401.

20. Wisch, M., Lerner, M., Kovaceva, J., Balint, A. et al., "Car-to-Cyclist Crashes in Europe and Derivation of Use Cases as Basis for Test Scenarios of Next Generation Advanced Driver Assistance Systems-Results from PROSPECT," in Proceedings of the 25th International Technical Conference on the Enhanced Safety of Vehicles (ESV), Detroit, MI, June 5-8, 2017.

21. Bunte, H. and Hipp, C., "Recumbent Bikes-Trikes-Velomobiles: An Analysis of (Single Vehicle) Crashes," in Proceedings of the International Cycling Safety Conference 2015, Hannover, Germany, September 15-16, 2015.

22. Ayres, T.J., "Analysis of Crash Reports for Recumbent Bicycles and Tricycles," Proceedings of the Human Factors and Ergonomics Society Annual Meeting 2019, no. 63 (2019): 12541258, https://doi.org/10.1177/1071181319631070.

23. Liers, H., Technical University Dresden, personal communication, 2020.

24. Billot-Grasset, A., Amoros, E., and Hours, M., "How Cyclist Behavior Affects Bicycle Accident Configurations?" Transportation Research Part F: Traffic Psychology and Behaviour 41 (2016): 261-276, https://doi.org/10.1016/j.trf.2015.10.007.

25. Moder, C., "Velomobil-Grundwissen (Velomobile-Basics)," accessed February 2, 2021, https://cmoder.gitlab.io/velomobil-grundwissen/Velomobil-Grundwissen.html.

26. Helak, K., Jehle, D., McNabb, D., Battisti, A. et al., "Factors Influencing Injury Severity of Bicyclists Involved in Crashes with Motor Vehicles: Bike Lanes, Alcohol, Lighting, Speed, and Helmet Use," Southern Medical Journal 7 (2017): 441-444.

27. Greenacre, M.J., Theory and Applications of Correspondence Analysis (London: Academic Press, 1989), ISBN:978-0122990502. 
28. Azim, R.A., Malik, F.M., and Syed, W.H., "Rollover Mitigation Controller Development for Three-Wheeled Vehicle Using Active Front Steering," Mathematical Problems in Engineering 6 (2015): 1-9, https://doi.org/10.1155/2015/918429.

29. Goodarzi, A., Soltani, A., Shojaeefard, M.H., and Khajepour, A., "An Integrated Vehicle Dynamic Control Strategy for Three-Wheeled Vehicles," Proceedings of the Institution of Mechanical Engineers, Part K: Journal of Multi-body Dynamics 229 (2015): 225-244, https://doi.org/10.1177/1464419314558741.

30. Thornley, S.J., Woodward, A., Langley, J.D., Ameratunga, S.N. et al., "Conspicuity and Bicycle Crashes: Preliminary Findings of the Taupo Bicycle Study," Injury Prevention: Journal of the International Society for Child and Adolescent Injury Prevention 14 (2008): 11-18, https://doi.org/10.1136/ip.2007.016675.

31. Abdur, R., Aya, K., Teppei, K., and Hisashi, K., "A Mechanism to Enhance Bicycle Conspicuity and Visibility and Increase Detection Distances: New Insights into Bicycle Safety," IATSS Research 45, no. 2 (2021): 241-250, https://doi.org/10.1016/j. iatssr.2020.09.006.

32. Dhondge, K., Song, S., Choi, B., and Park, H., "WiFiHonk: Smartphone-Based Beacon Stuffed WiFi Car2X-Communication System for Vulnerable Road User Safety," in 79th Vehicular Technology Conference (VTC Spring), Seoul, South Korea, 2014, https://doi. org/10.1109/VTCSpring.2014.7023146.

33. Engel, S., Kratzsch, C., and David, K., "Car2Pedestrian-Communication: Protection of Vulnerable Road Users Using Smartphones," in Advanced Microsystems for Automotive Applications, Fischer-Wolfarth, M., and Meyer, G., (Cham : Springer International Publishing, 2013), https://doi.org/10.1007/978-3-319-00476-1 4 .

\section{Appendix A: Survey}

Basic information

- Age

- Gender

- How many open multitrack bicycle vehicles (trikes) do you own?

- How many closed multitrack bicycle vehicles (velomobiles) do you own?

- What other multitrack bicycle vehicles do you use regularly?

- What is approximately your annual mileage with the vehicles queried here?

- How long have you been driving multitrack bicycle vehicles? (years)

- How many accidents/near-accidents have you had in this time? (In the context of this survey, a near-accident is an unusual dangerous situation that could have led to an accident under slightly different circumstances, e.g., leaving the road without consequences.)

Accident description

- Type of incident

- With which type of opponent did the accident occur?

- In which year did the incident occur?

- Has the incident been recorded by the police?

- In which season did the incident occur?

- Type of road (multiple selection possible, please refer to the accident description for additions or further explanations) 
- How were the road conditions? (multiple selection possible, please refer to the accident description for additions or further explanations)

- What type of vehicle was used? (if possible manufacturer's name or configuration: "2-wheels-front," "2-wheels-rear," "4-wheels")

- Can you give us information about the tires? (e.g., tire make, age, condition)

- How fast were you approximately at the time of the incident $(\mathrm{km} / \mathrm{h})$ ?

- Were there any personal injuries?

- What was the approximate damage to the vehicle in euros?

- What do you suspect is the cause of the accident? (multiple selection possible, please refer to the accident description for additions or further explanations)

- Please describe the circumstances of the accident as detailed as possible. (In addition to the description of the accident, you can also provide important additional information that may not have been covered by the questions, e.g., how could this accident have been avoided.) 


\section{Appendix B}

TABLE B.1 Relative incidence of accident characteristics per category.

\begin{tabular}{|c|c|c|c|c|c|c|}
\hline & & & Single $(N=33)$ & $\begin{array}{l}\text { With other party } \\
(N=34)\end{array}$ & $\begin{array}{l}\text { Single near }(N= \\
31)\end{array}$ & $\begin{array}{l}\text { Near with other } \\
\text { party }(N=25)\end{array}$ \\
\hline \multirow{47}{*}{$\begin{array}{l}\text { Answers given by } \\
\text { participant }\end{array}$} & \multirow[t]{5}{*}{ Season } & Spring & $15 \%$ & $21 \%$ & $16 \%$ & $16 \%$ \\
\hline & & Summer & $45 \%$ & $50 \%$ & $35 \%$ & $56 \%$ \\
\hline & & Fall & $21 \%$ & $18 \%$ & $16 \%$ & $12 \%$ \\
\hline & & Winter & $18 \%$ & $6 \%$ & $26 \%$ & $16 \%$ \\
\hline & & N/A & $0 \%$ & $6 \%$ & $3 \%$ & $0 \%$ \\
\hline & \multirow[t]{3}{*}{ Driving on } & Street & $67 \%$ & $82 \%$ & $74 \%$ & $88 \%$ \\
\hline & & Cycle path & $27 \%$ & $21 \%$ & $16 \%$ & $20 \%$ \\
\hline & & Others & $6 \%$ & $0 \%$ & $6 \%$ & $0 \%$ \\
\hline & \multirow[t]{7}{*}{ Road condition } & Uneven & $48 \%$ & $56 \%$ & $16 \%$ & $32 \%$ \\
\hline & & Even & $36 \%$ & $76 \%$ & $35 \%$ & $84 \%$ \\
\hline & & Dry & $39 \%$ & $32 \%$ & $35 \%$ & $52 \%$ \\
\hline & & Moist & $9 \%$ & $3 \%$ & $19 \%$ & $4 \%$ \\
\hline & & Wet & $6 \%$ & $3 \%$ & $6 \%$ & $4 \%$ \\
\hline & & Snowy & $3 \%$ & $0 \%$ & $10 \%$ & $0 \%$ \\
\hline & & Soiled & $15 \%$ & $0 \%$ & $6 \%$ & $0 \%$ \\
\hline & \multirow[t]{2}{*}{ Vehicle } & Velomobile & $76 \%$ & $68 \%$ & $74 \%$ & $68 \%$ \\
\hline & & Trike & $24 \%$ & $32 \%$ & $23 \%$ & $32 \%$ \\
\hline & \multirow[t]{8}{*}{ Velocity } & $0 \mathrm{~km} / \mathrm{h}$ & $0 \%$ & $18 \%$ & $0 \%$ & $0 \%$ \\
\hline & & $1-9 \mathrm{~km} / \mathrm{h}$ & $6 \%$ & $18 \%$ & $0 \%$ & $8 \%$ \\
\hline & & $10-19 \mathrm{~km} / \mathrm{h}$ & $12 \%$ & $15 \%$ & $13 \%$ & $8 \%$ \\
\hline & & $20-29 \mathrm{~km} / \mathrm{h}$ & $12 \%$ & $26 \%$ & $26 \%$ & $32 \%$ \\
\hline & & $30-39 \mathrm{~km} / \mathrm{h}$ & $55 \%$ & $15 \%$ & $32 \%$ & $32 \%$ \\
\hline & & $40-49 \mathrm{~km} / \mathrm{h}$ & $9 \%$ & $9 \%$ & $16 \%$ & $12 \%$ \\
\hline & & $50-59 \mathrm{~km} / \mathrm{h}$ & $0 \%$ & $0 \%$ & $3 \%$ & $8 \%$ \\
\hline & & $>60 \mathrm{~km} / \mathrm{h}$ & $6 \%$ & $0 \%$ & $6 \%$ & $0 \%$ \\
\hline & \multirow[t]{3}{*}{ Personal injuries } & No injuries & $55 \%$ & $56 \%$ & & \\
\hline & & Minor injuries & $39 \%$ & $26 \%$ & & \\
\hline & & $\begin{array}{l}\text { Ambulant } \\
\text { treatment }\end{array}$ & $6 \%$ & $18 \%$ & & \\
\hline & \multirow[t]{5}{*}{ Vehicle damage } & $€ 0$ & $24 \%$ & $24 \%$ & & \\
\hline & & $€ 1-€ 199$ & $18 \%$ & $12 \%$ & & \\
\hline & & $€ 200-€ 999$ & $39 \%$ & $24 \%$ & & \\
\hline & & $€ 1000-€ 1999$ & $12 \%$ & $21 \%$ & & \\
\hline & & $\geq € 2000$ & $6 \%$ & $21 \%$ & & \\
\hline & \multirow{9}{*}{$\begin{array}{l}\text { Causes of } \\
\text { accident (given } \\
\text { by participants) }\end{array}$} & High velocity & $52 \%$ & $6 \%$ & $65 \%$ & $4 \%$ \\
\hline & & $\begin{array}{l}\text { High steering } \\
\text { angle }\end{array}$ & $18 \%$ & $3 \%$ & $23 \%$ & $4 \%$ \\
\hline & & Strong braking & $6 \%$ & $0 \%$ & $3 \%$ & $0 \%$ \\
\hline & & Uneven road & $24 \%$ & $3 \%$ & $29 \%$ & $0 \%$ \\
\hline & & Slippery road & $33 \%$ & $0 \%$ & $32 \%$ & $0 \%$ \\
\hline & & Tire failure & $3 \%$ & $0 \%$ & $3 \%$ & $0 \%$ \\
\hline & & Vehicle failure & $0 \%$ & $3 \%$ & $0 \%$ & $0 \%$ \\
\hline & & Been overlooked & & $68 \%$ & & $68 \%$ \\
\hline & & Overlook others & & $9 \%$ & & $0 \%$ \\
\hline & \multirow[t]{5}{*}{ Opponent } & Car & & $62 \%$ & & $84 \%$ \\
\hline & & Motorcycle & & $9 \%$ & & $0 \%$ \\
\hline & & Truck & & $9 \%$ & & $8 \%$ \\
\hline & & Pedestrian & & $3 \%$ & & $8 \%$ \\
\hline & & Bicycle & & $18 \%$ & & $0 \%$ \\
\hline
\end{tabular}


TABLE B.1 (Continued). Relative incidence of accident characteristics per category.

\begin{tabular}{|c|c|c|c|c|c|c|}
\hline & & & Single $(N=33)$ & $\begin{array}{l}\text { With other party } \\
(N=34)\end{array}$ & $\begin{array}{l}\text { Single near }(N= \\
\text { 31) }\end{array}$ & $\begin{array}{l}\text { Near with other } \\
\text { party }(N=25)\end{array}$ \\
\hline \multirow[t]{14}{*}{$\begin{array}{l}\text { Categorization by } \\
\text { description }\end{array}$} & \multirow[t]{7}{*}{ Accident effect } & $\begin{array}{l}\text { Sliding/ } \\
\text { understeer }\end{array}$ & $15 \%$ & $0 \%$ & $19 \%$ & $0 \%$ \\
\hline & & $\begin{array}{l}\text { Avoidance } \\
\text { maneuver }\end{array}$ & $6 \%$ & $0 \%$ & $0 \%$ & $0 \%$ \\
\hline & & Tipping & $27 \%$ & $0 \%$ & $32 \%$ & $0 \%$ \\
\hline & & Loss of control & $15 \%$ & $0 \%$ & $19 \%$ & $0 \%$ \\
\hline & & $\begin{array}{l}\text { Incorrect } \\
\text { overtaking }\end{array}$ & $0 \%$ & $15 \%$ & $0 \%$ & $16 \%$ \\
\hline & & $\begin{array}{l}\text { Priority error } \\
\text { while turning }\end{array}$ & $0 \%$ & $29 \%$ & $0 \%$ & $52 \%$ \\
\hline & & Others & $3 \%$ & $18 \%$ & $0 \%$ & $24 \%$ \\
\hline & \multirow[t]{7}{*}{ Accident result } & Rollover & $79 \%$ & $0 \%$ & & \\
\hline & & $\begin{array}{l}\text { Collision with } \\
\text { surroundings }\end{array}$ & $21 \%$ & $0 \%$ & & \\
\hline & & Rear-end collision & $0 \%$ & $29 \%$ & & \\
\hline & & Side crash & $0 \%$ & $32 \%$ & & \\
\hline & & Touched vehicle & $0 \%$ & $18 \%$ & & \\
\hline & & Frontal crash & $0 \%$ & $12 \%$ & & \\
\hline & & Others & $0 \%$ & $9 \%$ & & \\
\hline
\end{tabular}

\section{Appendix C: Age Distribution of Survey Participants}

FIGURE C.1 Age distribution of survey participants.

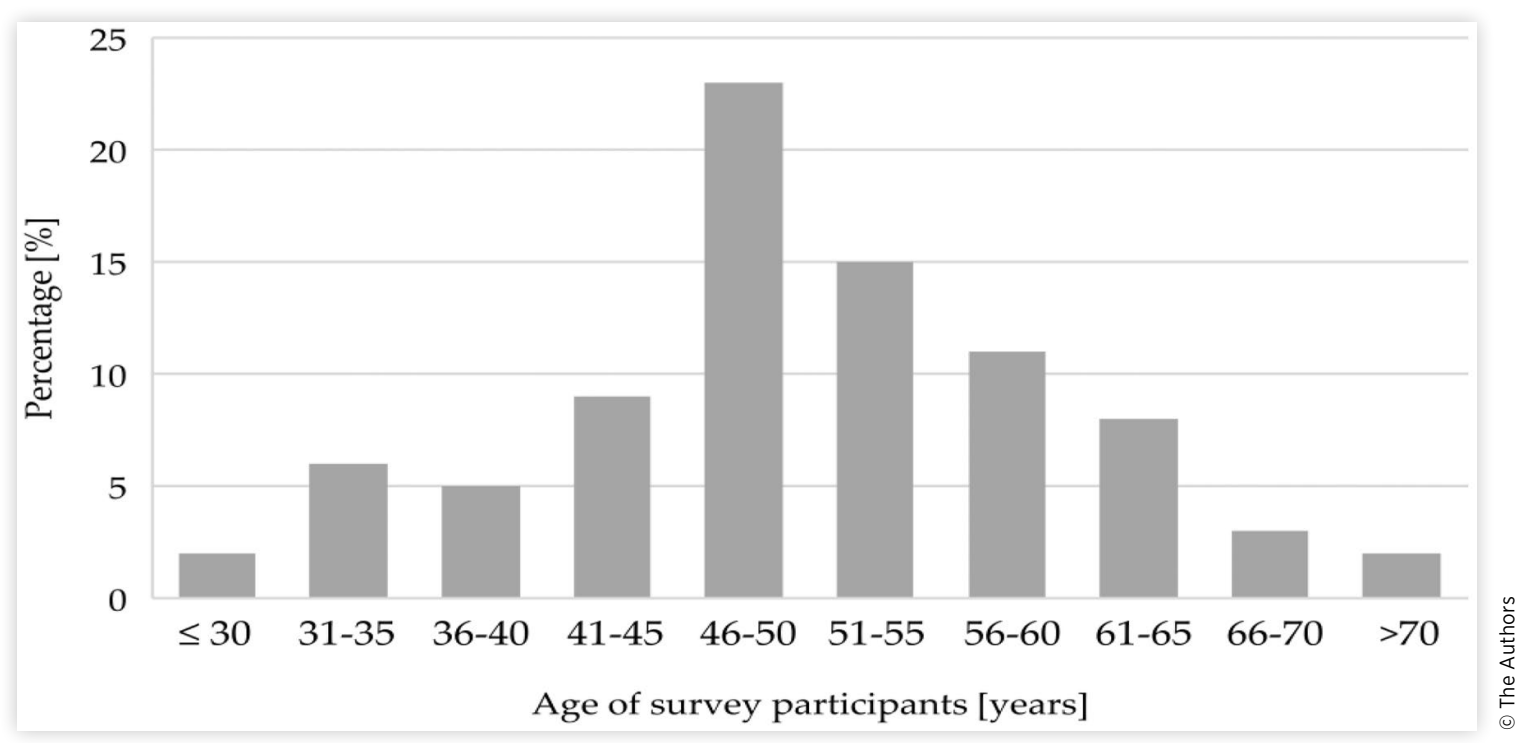

(c) 2022 The Authors. Published by SAE International. This Open Access article is published under the terms of the Creative Commons Attribution License (http:// creativecommons.org/licenses/by/4.0/), which permits distribution, and reproduction in any medium, provided that the original author(s) and the source are credited. 